\title{
Assessment of Multiple Tolerance Indices for Salinity Stress in Bread Wheat (Triticum aestivum L.)
}

\author{
Sanjay Singh ${ }^{1}$, R. S. Sengar ${ }^{2}$, Neeraj Kulshreshtha ${ }^{3}$, D. Datta ${ }^{4}$, R. S. Tomar ${ }^{5}$, V. P. Rao ${ }^{2}$, Deepa Garg ${ }^{6}$ \\ \& Ashish Ojha ${ }^{1}$ \\ ${ }^{1}$ Directorate of Wheat Research, Karnal, India \\ ${ }^{2}$ Sardar Vallabhbhai Patel University of Agriculture and Technology, Meerut, India \\ ${ }^{3}$ Central Soil Salinity Research Institute, Karnal, India \\ ${ }^{4}$ Indian Institute of Pulse Research, Regional Station, Bhopal, India \\ ${ }^{5}$ National Research Centre on Plant Biotechnology, New Delhi, India \\ ${ }^{6}$ Kurushhetra University, Kurushhetra, India \\ Correspondence: Sanjay Singh, Quality Lab, Directorate of Wheat Research, Karnal 132001, India. Tel: \\ 91-829-501-0039. E-mail: sanjaydbtster@gmail.com
}

\author{
Received: November 19, 2014 Accepted: December 19, 2014 Online Published: February 15, 2015 \\ doi:10.5539/jas.v7n3p49 \\ URL: http://dx.doi.org/10.5539/jas.v7n3p49
}

\begin{abstract}
Salinity is one of the major factors reducing plant growth and productivity worldwide and affects about $7 \%$ of world's total land area. In India about 6.73 million hectare of land area is salt affected. Wheat is the second most important crop after rice in India and occupies approximately 28.5 million hectare area. Several tolerance indices comprising of mean productivity (MP), geometric mean productivity (GMP), stress tolerance index (STI), stress stability index (SSI), tolerance index (TOL), yield index (YI) and yield stability index (YSI) were calculated in this investigation for salinity and its ability to understand which one or more predictor among studied indices based on correlation, principal component analysis and cluster analysis. Ten wheat genotypes were evaluated in two successive growing seasons (2012-2014), with complete randomized design with three replications under both salinity stress and non-salinity to identify salt tolerant genotypes to the target environment. Multiple indices for salt tolerance were calculated based on the potential yield (Yp) under non-stress and yield (Ys) under stress conditions. The Ys and Yp showed highest significant and positive correlations with GMP, MP and STI among indices studied. Therefore, these indices were considered as a better predictor of Ys and Yp than TOL, SSI and YSI. Principal component analysis classified the genotypes into two groups. The first two PCs with eigen values $>1$ contributed $99.74 \%$ of the variability amongst genotypes. PC1 accounted for about $5.24 \%$ of the variation in salt tolerance indices and PC2 for 3.74\%. The first PC was related to Ys, Yp, MP, GMP, STI and YI whereas the second PC related to Yp, TOL and SSI. The cluster analysis sequestrated ten genotypes into two clusters based on Ward's method. According to results, salinity significantly reduced the yield of some genotypes while some were found tolerant to stress indicating sufficient genetic variability for salinity tolerance among the studied genotypes. It could be implicated in selection of salinity tolerant wheat genotypes for the development of bread wheat varieties.
\end{abstract}

Keywords: bread wheat, grain yield, principal component, salt tolerance indices

\section{Introduction}

Among abiotic stress, salinity is one of the major factors reducing plant growth and productivity worldwide, and affects about $7 \%$ of world's total land area (Flowers et al., 1997). Percentage of cultivated land affected by salt is even greater, with $23 \%$ of the cultivated land being saline and $20 \%$ of the irrigated land suffering from secondary salinization. Furthermore, there is also a dangerous trend of a $10 \%$ per year increase in the saline area throughout the world (Ponnamieruma, 1984). In India about 6.73 million hectare land area is salt affected out of which 3.77 and 2.96 million hectare are afflicted by sodicity and salinity, respectively (Mondal et al., 2010). Wheat is the second most important crop after rice in India and occupies approximately 28.5 million hectare area (Singh, 2012). According to estimates FAO $(2006,2007)$ and Rosegrant et al. (2001), the global wheat production must increase by at least 1.6 per cent annually during 2010-2020 to meet a projected wheat demand of 760 million 
tons by 2020. In order to achieve this goal therefore, improving wheat productivity will be essential to meet the growing demand for food under shrinking cultivable land area. It is imperative in this context to look for tools not only to increase the crop productivity but also ensure protection against loss of potential productivity due to environmental vagaries (Kumar et al., 2012). Several selection criteria have been proposed for selecting genotypes based on their performance in stress and non-stress environments (Fischer \& Maurer, 1978; Rosielle \& Hamblin, 1981; Fernandez, 1992). Some researchers recommend selection under favourable environments, with a point of view that high yield potential is expected to sustain high yields under stress environments (Richards, 1996; Van-Ginkel et al., 1998; Betran et al., 2003). Many scientists have chosen a compromise solution and believe in selection under both stress and non-stress conditions (Fischer \& Mourer, 1978; Clarke et al., 1992; Fernandez, 1992; Mitra, 2001; Mohammadi et al., 2010; Nouri et al., 2011). Fischer and Mourer (1978) proposed a stress susceptibility index (SSI) and showed that it is not independent of yield potential. Rosielle and Hamblin (1981) introduced a stress tolerance index (TOL) based on the differences in yields measured under non-stress (Yp) and stress (Ys) conditions. Rosielle and Hamblin (1981) defined mean productivity index (MP) as the average of Yp and Ys. But MP has an upward bias when there are larger differences between Yp and Ys. The geometric mean productivity (GMP), which is less sensitive to extreme values, is a better indicator than MP for separating superior genotypes in both stress and non-stress environments (Rosielle \& Hamblin, 1981). Fernandez defined a new stress tolerance index (STI), which can be used to identify genotypes which produce high yields under both stress and non-stress conditions. For selection based on a combination of indices, some researchers (Golabadi et al., 2006; Azizi Chakherchaman et al., 2009; Majidi et al., 2011) have used principal component analysis (PCA). PCA is one of the most successful techniques for reducing the multiple dimensions of the observed variables to a smaller intrinsic dimensionality of independent variables (Johnson \& Wichern, 2007). These tolerance indices have been widely used in different regions for the evaluation of wheat genotypes (Mohammadi et al., 2010; Mohammadi et al., 2011; Khakwani et al., 2011; Anwar et al., 2011) for drought but very limited work has been reported till date for salinity tolerance. To improve wheat yield and its stability in stress environments, there is a need to identify selection indices able to distinguish high yielding wheat cultivars in these conditions. Thus, the aim of this study was to evaluate the effectiveness of several salinity tolerance indices for screening and identification of salt tolerance wheat genotypes.

\section{Materials and Methods}

\subsection{Experimental Arrangement and Plant Material}

Pot experiment was laid out by planting ten bread wheat genotypes (Table 1), based on highly contrasting morphological feature obtained from gene pool of Central Soil Salinity Research Institute (CSSRI), Karnal, and Sardar Vallabhbhai Patel University of Agriculture and Technology (SVPUA\&T), Meerut, India. The experiment was laid out at the experimental farm, Department of Agriculture Biotechnology, SVPUA\&T, Meerut, during November, 2012-13 and 2013-14. Experimental soil was sandy loam with initial pH 7.2 and ECe $1.13 \mathrm{dSm}^{-1}$. To create the irrigation water of desired salinity level $\left(\mathrm{EC}_{\mathrm{iw}}=10.0 \mathrm{dSm}{ }^{-1}\right)$, required quantity of $\mathrm{NaCl}, \mathrm{Na}_{2} \mathrm{SO}_{4}$ and $\mathrm{CaCl}_{2}(7: 1: 2)$ were thoroughly mixed with irrigating water $\left(\mathrm{EC}_{\mathrm{iw}}=10.0 \mathrm{dSm}{ }^{-1}\right)$, to the pots. The pot experiment was performed in complete randomized design (CRD) with three replications of two sets. Two level of soil salinity i.e, control (normal irrigation water) and saline (pre sowing with normal water and saline irrigation after 21 days of sowing) condition.

Table 1. The detailed information of genotypes includes for study

\begin{tabular}{lllll}
\hline Ser. No. & Genotypes & Parentages & Developed by & Year \\
\hline 1 & Kharchia 65 & Kharchia Local/ EG 953 & DURGAPURA & 1970 \\
2 & HD 2009 & LR 64A/ NAI60 & N. DELHI & 1975 \\
3 & PBW 343 & ND/VG9144//KAL/BB/3/YCO'S'/4/VEE\#5 'S' & LUDHIANA & 1995 \\
4 & AKAW 4627 & WH 147/SUNSTAR */C 80.1 & AKOLA & 2010 \\
5 & K 9423 & HP1633/KAL/UP262 & KANPUR & 2004 \\
6 & PBW 373 & ND/VG9144//KAL/BB/3/YCO'S'/4/VEE \# 5 'S' & LUDHIANA & 1996 \\
7 & HUW 468 & CPAN 1962/TONI//LIRA'S/PRL'S & VARANASI & 1999 \\
8 & K9162 & K 7827/HD 2204 & KANPUR & 1999 \\
9 & PBW 154 & HD 2160/HD 2177 & LUDHIANA & 1988 \\
10 & UP 1109 & UP262/UP 368 & PANTNAGAR & 1985 \\
\hline
\end{tabular}




\subsection{Estimation of Salt Tolerance Indices}

Salt tolerance indices for each genotype were calculated using the following formulas:

Yield stability index $(Y S I)=Y_{s} / Y_{p}$ (Bouslama \& Schapaugh, 1984);

Yield index $(Y I)=Y_{S} / \bar{Y}_{S}$ (Gavuzzi et al., 1997);

Stress tolerance index $(S T I)=Y_{p} \times Y_{s} / \bar{Y}_{p}^{2}($ Fernandez, 1992);

Geometric mean productivity $(G M P)=\sqrt{Y p} \times Y_{s}$ (Fernandez, 1992);

Stress susceptibility index $(S S I)=\left(1-Y_{S} / Y_{p}\right) / S I ; S I=1-\bar{Y}_{S} / \bar{Y}_{p}$ (Fischer \& Maurer, 1978);

Mean productivity $(M P)=\frac{Y p+Y s}{2}($ Rosielle \& Hamblin, 1981);

Tolerance index $(T O L)=Y_{p}-Y_{s}($ Rosielle \& Hamblin, 1981).

Where $Y_{s}$ and $Y_{p}$ are the yields of genotypes evaluated under saline (stress) and non-saline (non-stress) conditions and $\bar{Y}_{s}$ and $\bar{Y}_{p}$ are the mean yields of all genotypes evaluated under stress and non-stress conditions, respectively.

\subsection{Statistical Analysis}

The combined data of grain yield both under stress and non-stress conditions were subjected to analysis to estimate the simple statistic i.e., mean, standard error and simple correlation. Salt tolerance indices were analyzed by cluster and principal component analysis with the help of Software program 'SPSS' v 16.0 for windows. Cluster analysis identifies variable which are further clustered into main group and subgroups using Ward's method (Kumar et al., 2009). The genotypes in each cluster were also analyzed for basic statistics. This was done to interpret relationships among selection criteria, to compare genotypes on the basis of salt tolerance indices and to identify genotypes or groups of genotypes with a certain level of salt tolerance. All the statistical analysis was performed using SPSS v 16.0 (SPSS Inc., 2007, Chicago, IL, USA) software programme.

\section{Result and Discussion}

The pooled data of two-year (2012-14) revealed that mean grain yield of bread wheat genotypes varied from 2.95 to $5.35 \mathrm{gm} \mathrm{plant}^{-1}$ under stress environment, while mean yield of genotypes under non-stressed environment varied from 6.50 to $13.30 \mathrm{gm}_{\text {plant }}{ }^{-1}$. The genotypes G1, G10, G7, G8 and G2 had the best performance for grain yield in salt stressed conditions, while the genotypes G10, G7, G8, G6, and G2 had the best performance under non-stressed conditions, respectively (Table 2). The genotypes also exhibited highly significant differences for all the salt tolerance indices (Table 3). The two-year mean values of screening methods for characterizing salt tolerance and adaptation of genotypes to different environments are presented in Table 2 . The highest TOL value was calculated for G7, followed by G10, G8, G9 and G6, indicating that these genotypes had a greater grain yield (GY) reduction under salt stress condition and higher salt sensitivity, whereas the lowest TOL value was found in G1, followed by G2, G3, G4 and G5, indicating these genotypes had a lower GY reduction in stress condition. According to SSI, the genotype G9, followed by G7, G8, G6 and G5 had the highest values, while genotype G1, followed by G3, G2, G6 and G4 had the lowest values, and were considered as genotypes with high salt susceptibility and poor yield stability in both stress and non-stress conditions. Based on ranking of MP, STI and GMP indices, genotypes G10, G7, G8, G6 and G2 had the highest values, whereas the genotypes remained had the lowest values. Similar ranks of the genotypes for MP and GMP parameters as well as STI suggest that these three indices are comparable for selecting genotypes. The highest YSI was obtained by genotype G1, followed by G3, G2, G10 and G4, whereas the lowest YSI was obtained for genotype G9, followed by G7, G8, G6 and G5. The genotype G1, followed by G10, G7, G8 and G6 had the highest YI and the genotype G2, followed by G9, G5, G4 and G3 had the lowest YI value. 
Table 2. The mean of pool data of two years (2012-14) of grain yield of ten bread wheat genotypes under stressed and non-stressed environments and their corresponding tolerance indices

\begin{tabular}{llllllllll}
\hline Genotypes & Ys & Yp & TOL & MP & GMP & SSI & STI & YSI & YI \\
\hline G1 & $5.35(1)$ & $7.40(9)$ & $2.05(10)$ & $10.08(7)$ & $6.29(5)$ & $0.46(10)$ & $0.41(5)$ & $0.72(1)$ & $1.36(1)$ \\
G2 & $2.95(10)$ & $6.50(10)$ & $3.55(9)$ & $7.98(10)$ & $4.38(10)$ & $0.91(8)$ & $0.20(10)$ & $0.45(3)$ & $0.75(10)$ \\
G3 & $3.50(6)$ & $7.60(8)$ & $4.10(8)$ & $9.35(9)$ & $5.16(8)$ & $0.90(9)$ & $0.274(8)$ & $0.46(2)$ & $0.89(6)$ \\
G4 & $3.35(7)$ & $8.65(6)$ & $5.30(7)$ & $10.33(6)$ & $5.38(7)$ & $1.02(6)$ & $0.30(7)$ & $0.39(5)$ & $0.85(7)$ \\
G5 & $3.10(8)$ & $8.50(7)$ & $5.40(6)$ & $10.05(8)$ & $5.13(9)$ & $1.058(5)$ & $0.272(9)$ & $0.365(6)$ & $0.79(8)$ \\
G6 & $4.20(5)$ & $11.55(4)$ & $7.35(5)$ & $13.65(4)$ & $6.96(4)$ & $1.060(4)$ & $0.50(4)$ & $0.364(7)$ & $1.07(5)$ \\
G7 & $4.30(3)$ & $12.80(2)$ & $8.50(1)$ & $14.95(2)$ & $7.42(2)$ & $1.11(2)$ & $0.57(2)$ & $0.34(9)$ & $1.09(3)$ \\
G8 & $4.25(4)$ & $11.75(3)$ & $7.50(3)$ & $13.88(3)$ & $7.07(3)$ & $1.063(3)$ & $0.51(3)$ & $0.362(8)$ & $1.08(4)$ \\
G9 & $3.05(9)$ & $10.45(5)$ & $7.40(4)$ & $11.98(5)$ & $5.65(6)$ & $1.18(1)$ & $0.33(6)$ & $0.29(10)$ & $0.78(9)$ \\
G10 & $5.30(2)$ & $13.30(1)$ & $8.00(2)$ & $15.95(1)$ & $8.40(1)$ & $1.00(7)$ & $0.73(1)$ & $0.40(4)$ & $1.35(2)$ \\
\hline Std. Error & 0.28 & 0.77 & 0.69 & 0.84 & 0.40 & 0.06 & 0.05 & 0.04 & 0.07 \\
\hline
\end{tabular}

Note. The numbers in the parentheses are the ranks of the genotype for each index.

Ys - grain yield under stressed environment, Yp - Grain yield under non-stressed environment, SI - stress intensity, MP - mean productivity, GMP - geometric mean productivity, STI - stress tolerance index, SSI stress susceptibility index, TOL - tolerance index, YSI - yield stability index, YI - yield index.

Table 3. Relationships among traits studied in this investigation

\begin{tabular}{|c|c|c|c|c|c|c|c|c|}
\hline Tolerance Indices & Ys & $\mathrm{Yp}$ & TOL & MP & GMP & SSI & STI & YSI \\
\hline$\overline{Y p}$ & $0.459^{\mathrm{ns}}$ & & & & & & & \\
\hline TOL & $0.103^{\mathrm{ns}}$ & $0.931^{* *}$ & & & & & & \\
\hline MP & $0.586^{\mathrm{ns}}$ & $0.989^{* *}$ & $0.866^{* *}$ & & & & & \\
\hline GMP & $0.810^{* *}$ & $0.892^{* *}$ & $0.665^{*}$ & $0.949^{* *}$ & & & & \\
\hline SSI & $-0.485^{\mathrm{ns}}$ & $0.548^{\mathrm{ns}}$ & $0.813^{* *}$ & $0.418^{\mathrm{ns}}$ & $0.119^{\mathrm{ns}}$ & & & \\
\hline STI & $0.804^{* *}$ & $0.886^{* *}$ & $0.661^{*}$ & $0.942^{* *}$ & $0.995^{* *}$ & $0.123^{\mathrm{ns}}$ & & \\
\hline YSI & $0.491^{\mathrm{ns}}$ & $-0.542^{\mathrm{ns}}$ & $-0.809^{* *}$ & $-0.412^{\mathrm{ns}}$ & $-0.111^{\mathrm{ns}}$ & $-1.000^{* *}$ & $-0.115^{\mathrm{ns}}$ & \\
\hline YI & $1.000^{* *}$ & $0.461^{\mathrm{ns}}$ & $0.105^{\mathrm{ns}}$ & $0.588^{\mathrm{ns}}$ & $0.811^{* *}$ & $-0.484^{\mathrm{ns}}$ & $0.805^{* *}$ & $0.490^{\mathrm{ns}}$ \\
\hline
\end{tabular}

Note. ns, ${ }^{*}$ and $* *$ non-significant and significant at the $5 \%$ and $1 \%$ levels of probability, respectively.

Ys - grain yield under stressed environment, Yp - Grain yield under non-stressed environment, SI - stress intensity, MP - mean productivity, GMP - geometric mean productivity, STI - stress tolerance index, SSI stress susceptibility index, TOL - tolerance index, YSI - yield stability index, YI - yield index.

\subsection{Correlation Analysis}

The mean yield of ten genotypes in the stressed environment was reduced by $40 \%$ compared to the non-stressed environment, indicating that the genotypes experienced a moderate salt stress. The yield under salt-stressed conditions (Ys) had a very weak association with the yield under non-stressed conditions (Yp), indicating that high potential yield under optimal conditions does not necessarily result in improved yield in a salinity-prone environment. For example, the genotypes G10, G7, G8 and G6 produced the highest yield under non-stressed conditions but failed to produce high yields in the stressed environment. Therefore, indirect selection for such conditions based on the results of optimum conditions will not be efficient. These results are supported by Gholipouri et al. (2009), Karimizadeh et al. (2011) and Anwar et al. (2011) who found a positive but non-significant association between yield in stress and non-stress environments. The results showed that the greater the TOL and SSI values, the higher the yield under non-stressed conditions and conversely, there was a trend for smaller TOL and SSI values to be associated with larger yield production under stressed conditions 
(Table 2). These relationships are obvious in Table 3, in that Yp significantly and positively correlated with TOL and SSI, but Ys correlated negatively with SSI and TOL. These results suggest that selection based on low values of TOL and SSI will result in reduced yield under non-stressed conditions. Similar results were reported by Clark et al. (1992), Sio-Se Mardeh et al. (2006), Talebi et al. (2009) and Karimizadeh et al. (2011). Grain yield under stressed conditions (Ys) and non-stressed conditions (Yp) were significantly and positively correlated with MP, GMP and STI, which indicated that they were better predictors of Ys and Yp than TOL and SSI. The indices, MP, GMP and STI were able to identify high yielding wheat genotypes in both stressed and non-stressed conditions and these findings are consistent with the findings of Fernandez (1992), Mohammadi et al. (2003), Golabadi et al. (2006), Mohammadi et al. (2010) and Nouri et al. (2011). These three indices were correlated with yield under both environments (Table 3).The YI and YSI were significantly and positively correlated with Ys, and negatively correlated with TOL and SSI (Table 3), indicating that these two indices are useful to discriminate salt tolerant and yield stable genotypes. Mohammadi et al. (2010) was found that YSI to be a more useful index to discriminate tolerant from susceptible genotypes due to its negative correlation with TOL and SSI. Bansal and Sinha (1991) used SSI as stability parameter to identify drought-resistant genotypes of wheat. In this study, genotype G1, followed by G3, G2, G10 and G4 had the lowest SSI values and therefore, these genotypes have low salt susceptibility and high yield stability in both conditions, whereas the genotype G9, followed by G4, G8, G6 and G5 had the highest SSI value can be considered as genotypes with high salt susceptibility and poor yield stability in both stress and non-stress conditions. Similar results were reported in durum wheat by Golabadi et al. (2006), Talebi et al. (2009) and Nouri et al. (2011) for drought tolerance evaluation.

\subsection{Cluster and Principal Component Analysis}

Germplasm improvement and genetic diversity is the key to reliable and sustainable production of the food crops. For effective evaluation and utilization of germplasm, measure of extent of available genetic diversity is of utmost importance (Zubair et al., 2007). The use of multivariate statistical algorithms is an important strategy for classification of germplasm and analysis of genetic relationships among breeding material (Mohammadi \& Prasanna, 2003). In order to maintain, evaluate and utilize germplasm effectively, it is important to investigate the extent of genetic diversity available. The cluster analysis sequestrates genotypes into clusters which exhibit high homogeneity within a cluster and high heterogeneity between clusters (Jaynes et al., 2003). Cluster analysis (Ward's method) based on salt tolerance indices and grain yield under stressed and non-stressed conditions classified the genotypes into two groups (Figure 1) with five genotypes, each respectively. Within group genotypes show minimum variance and genetic distance, while between-group genotypes are dissimilar with maximum genetic distance (Table 5). Phylogenetic (genetic) distance between cluster I and cluster II centres were 7.46. Members of each cluster are presented in Table 5. Mean values along with standard deviation for each cluster (Table 5) revealed that genotypes in the cluster II showed moderate to highly salinity susceptible than genotypes in cluster I because mean value of YSI of cluster II higher than mean value of final cluster and cluster I (Table 4). Similar results were obtained by various researchers worldwide previously i.e., Leilah and Al-Khateeb (2005) used seven statistical procedures to study the relationship between wheat grain yield and its components. Seventy wheat genotypes were evaluated for variability parameter including cluster analysis for eight traits by Ali et al. (2008). Aharizad et al. (2012) applied cluster analysis using Wards algorithm and squared Euclidean distances and assigned 94 bread wheat inbred lines into three groups. 


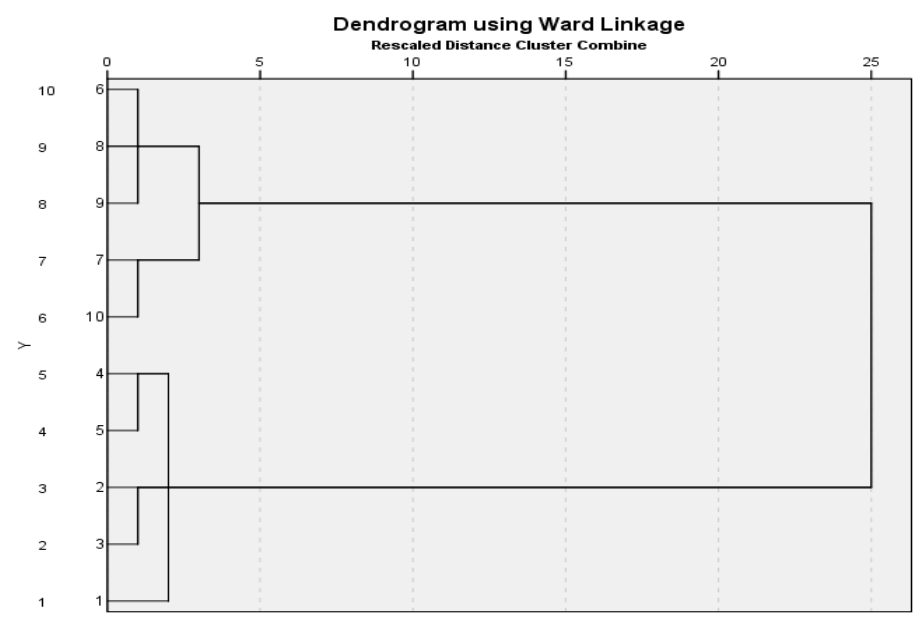

Figure 1. Dendrogram resulting from cluster analysis of bread wheat genotypes based on studied trait

Table 4. Mean and standard deviation for clusters based on nine studied characters

\begin{tabular}{llll}
\hline Traits & Both clusters (I+II) & Cluster I & Cluster II \\
\hline Ys & $3.9350 \pm 0.89$ & $3.6500 \pm 0.97$ & $4.2200 \pm 0.79$ \\
Yp & $9.8500 \pm 2.42$ & $7.7300 \pm 0.87$ & $11.9700 \pm 1.11$ \\
TOL & $5.9150 \pm 2.16$ & $4.0800 \pm 1.38$ & $7.7500 \pm 0.49$ \\
MP & $11.8200 \pm 2.66$ & $9.5580 \pm 0.95$ & $14.0820 \pm 1.49$ \\
GMP & $6.1840 \pm 01.2$ & $5.2680 \pm 0.68$ & $7.1000 \pm 0.98$ \\
SSI & $0.9760 \pm 0.19$ & $0.8700 \pm 0.23$ & $1.0820 \pm 0.06$ \\
STI & $0.4090 \pm 0.16$ & $0.2900 \pm 0.07$ & $0.5280 \pm 0.14$ \\
YSI & $0.4130 \pm 0.11$ & $0.4760 \pm 0.14$ & $0.3500 \pm 0.04$ \\
YI & $1.0010 \pm 0.22$ & $0.9280 \pm 0.24$ & $1.0740 \pm 0.20$ \\
\hline
\end{tabular}

Table 5. Grouping of genotypes based on nine studied characters

\begin{tabular}{llll}
\hline Cluster & Frequency & Dendrogram representing no. & Cluster membership \& distance \\
\hline I & 5 & $1,2,3,4,5$ & Kharchia 65(2.97), HD 2009(2.36), PBW 343(0.31), \\
& & AKAW 4627(1.75) and K 9423(1.72) & \\
II & 5 & $6,7,8,9,10$ & $\begin{array}{l}\text { PBW 373(0.73), HUW 468(1.45), K9162(0.39), PBW } \\
154(3.23) \text { and UP 1109(2.88) }\end{array}$
\end{tabular}

In addition to correlation analysis, principal component analysis based on salt tolerance indices was constructed to identify superior genotypes for both stressed and non-stressed environments. Principal component analysis simplifies the complex data by transforming the number of correlated variables into a smaller number of variables called principal components. The first principal component accounts for maximum variability in the data with respect to succeeding components (Leilah \& Al-Khateeb, 2005). The analysis had grouped the estimated wheat variables into two main components. The first two components with eigen values $>1$ accounted for $99.74 \%$ of the total variation of grain yield. $\mathrm{PC} 1$ accounted for about $5.24 \%$ of the variation in salt tolerance indices and PC2 for 3.74\% (Table 6). The first PC was related to Ys, Yp, MP, GMP, STI and YI whereas the second PC related to Yp, TOL and SSI (Table 6). The first PC was negatively related to SSI while PCII was negatively related to Ys, YSI and YI. MP, GMP, STI, TOL and SSI were strongly correlated with yield under normal irrigation and have significantly negative correlations with YSI, indicating that these indices are able to select salt susceptible genotypes which only perform well under non-stressed conditions and have poor yield stability. Ys has a significantly positive correlation with YSI, MP, GMP and STI, and a significantly negative correlation with SSI, indicating that these indices are also able to select salt tolerant genotypes which performed 
well under stressed conditions and have low to moderate yield stability. Results are in agreement with Ahmad et al. (2008) who evaluated 113 accessions of barley by using cluster and principal component analysis.

Table 6. Principal component analysis for Ys, Yp and tolerance indices of ten bread wheat genotypes (pooled data of two years)

\begin{tabular}{lll}
\hline Traits & Component 1 & Component 2 \\
\hline Ys & 0.902 & -0.431 \\
Yp & 0.797 & 0.602 \\
TOL & 0.522 & 0.851 \\
MP & 0.878 & 0.477 \\
GMP & 0.983 & 0.180 \\
SSI & -0.063 & 0.997 \\
STI & 0.979 & 0.182 \\
YSI & 0.070 & -0.996 \\
YI & 0.903 & -0.429 \\
Eigen value & 5.241 & 3.735 \\
Percent of variation & 58.233 & 41.502 \\
Cumulative percentage & 58.233 & 99.735
\end{tabular}

Note. Ys - grain yield under stressed environment, Yp - Grain yield under non-stressed environment, SI - stress intensity, MP - mean productivity, GMP - geometric mean productivity, STI - stress tolerance index, SSI stress susceptibility index, TOL - tolerance index, YSI - yield stability index, YI - yield index.

\section{Conclusion}

According to results, salinity significantly reduced the yield of some genotypes while some were tolerant to stress indicating that sufficient genetic variability was present for salinity tolerance among the studied genotypes. Based on correlation and principal component analysis it can be concluded that MP, GMP and STI were the best indicators of yield under both stressed and non-stressed environments because these indices had positive and significant correlations with Ys and Yp. Suitable genotypes can be selected both under stressed and non-stressed conditions using MP, GMP and STI indices as a means to combine information on performance.

\section{Acknowledgements}

The authors gratefully acknowledge the Central Soil Salinity Research Institute (CSSRI), Karnal, India for providing valuable genotypes for the present study. The authors are also grateful to Prof. H. S. Gaur, Vice Chancellor, SVPUA\&T, Meerut, for providing facilities to conduct research work (Ph.D) in the Department of Agriculture Biotechnology.

\section{References}

Aharizad, S., Sabzi, M., Mohammadi, S. A., \& Khodadadi, E. (2012). Multivariate analysis of genetic diversity in wheat (Titicum aestivum L.) recombinant inbred lines using agronomic traits. Annals Biol. Res, 3(5), 2118-2126.

Ahmad, Z., Ajmal, S. U., Munir, M., Zubair, M., \& Masood, M. S. (2008). Genetic diversity for morpho-genetic traits in barley germplasm. Pak. J. Bot, 40, 1217-1224.

Ali, Y., Atta, M. B., Akhter, J., Monneveux, P., \& Lateef, Z. (2008). Genetic variability, association and diversity studies in wheat (Triticum aestivum L.) germplasm. Pak. J. Bot, 40, 2087-2097.

Anwar, J., Subhani, G. M., Hussain, M., Ahmad, J., Hussain, M., \& Munir, M. (2011). Drought tolerance indices and their correlation with yield in exotic wheat genotypes. Pak. J. Bot, 43, 1527-1530.

Azizi-Chakherchaman, S. H., Mostafaei, H., Imanparast, L., \& Eivazian, M. R. (2009). Evaluation of drought tolerance in lentil advanced genotypes in Ardabil region. $J$ Food Agric Environ, 7, 283-288. 
Bansal, K. C., \& Sinha, S. K. (1991). Assessment of drought resistance in 20 accessions of Triticum aestivumand related species total dry matter and grain yield stability. Euphytica, 56, 7-14.

Betran, F. J., Beck, D., Banziger, M., \& Edmeades, G. O. (2003). Genetic analysis of inbred and hybrid grain yield under stress and non-stress environments in tropical maize. Crop Sci, 43, 807-817.

Bouslama, M., \& Schapaugh, W. T. (1984). Stress tolerance in soybean. Part. 1: Evaluation of three screening techniques for heat and drought tolerance. Crop Sci, 24, 933-937.

Clarke, J. M., DePauw, R. M., \& Townley-Smith, T. F. (1992). Evaluation of methods for quantification of drought tolerance in wheat. Crop Sci, 32, 728-7232.

FAO. (2006). World Agriculture towards 2030/2050 Interim report. Global Perspective Studies Unit, FAO, Rome.

FAO. (2007). Retrieved September, 2007, from http://faostat.fao.org/faostat/\&nbsp

Fernandez, G. C. J. (1992). Effective selection criteria for assessing stress tolerance. In C. G. Kuo (Ed.), Proceedings of the International Symposium on Adaptation of Vegetables and Other Food Crops in Temperature and Water Stress. Publication, Tainan, Taiwan.

Fischer, R. A., \& Maurer, R. (1978). Drought resistance in spring wheat cultivars. I. Grain yield response. Aust J Agric Res, 29, 897-907.

Flowers, T. J., Garcia, A., Koyama, M., \& Yeo, A. R. (1997). Breeding for salt tolerance in crop plants, the role of molecular biology. Acta Physiol. Plant, 19(4), 427-433.

Gavuzzi, P., Rizza, F., Palumbo, M., Campaline, R. G., Ricciardi, G. L., \& Borghi, B. (1997). Evaluation of field and laboratory predictors of drought and heat tolerance in winter cereals. Canadian J. Plant Sci, 77, 523-531.

Gholipouri, A., Sedghi, M., Sharifi, R. S., \& Nazari, N. M. (2009). Evaluation of drought tolerance indices and their relationship with grain yield in wheat cultivars. Recent Res Sci. \& Technol, 1, 195-198.

Golabadi, M., Arzani, A., \& Maibody, S. A. M. (2006). Assessment of drought tolerance in segregating populations in durum wheat. Afr. J. Agric. Res, 5, 162-171.

Jaynes, D. B., Kaspar, T. C., Colvin, T. S., \& James, D. E. (2003). Cluster analysis of spatiotemporal corn yield pattern in an Iowa field. Agron J, 95, 574-586.

Johnson, R. A., \& Wichern, D. W. (2007). Applied Multivariate Statistical Analysis (6th ed.). Prentice-Hall International, Englewood Cliffs, NJ, USA.

Karimizadeh, R., Mohammadi, M., Ghaffaripour, S., Karimpour, F., \& Shefazadeh, M. K. (2011). Evaluation of physiological screening techniques for drought-resistant breeding of durum wheat genotypes in Iran. Afr. $J$. Biotechnol, 10, 12107-12117.

Khakwani, A. Z., Dennett, M. D., \& Munir, M. (2011). Drought tolerance screening of wheat varieties by inducing water stress conditions. Songklanakarin J. Sci. \& Technol., 33, 135-142.

Kumar, B., Lal, G. M., Ruchi, \& Upadhyay, A. (2009). Genetic variability, diversity and association of quantitative traits with grain yield in bread wheat (Triticum aestivum L.). Asian Journal of Agricultural Sciences, 1(1), 4-6.

Kumar, S., Singh, R., Grover, M., \& Singh A. K. (2012). Terminal heat-an emerging problem for wheat production. Biotech Today, 2(2), 7-9.

Leilah, A. A., \& Al-Khateeb, S. A. (2005). Statistical analysis of wheat yield under drought conditions. Elsevier, 61, 483-496.

Majidi, M. M., Mirlohi, A., \& Amini, F. (2009). Genetic variation, heritability and correlations of agro-morphological traits in tall fescue (Festuca arundinacea Schreb). Euphytica, 167, 323-331.

Mitra, J. (2001). Genetics and genetic improvement of drought resistance in crop plants. Current Sci., 80, 758-762.

Mohammadi, M., Karimzadeh, R., \& Abdipour, M. (2011). Evaluation of drought tolerance in bread wheat genotypes under dryland and supplemental irrigation conditions. Aust. J. Crop Sci., 5, 487-493.

Mohammadi, R., Armion, M., Kahrizi, D., \& Amri, A. (2010). Efficiency of screening techniques for evaluating durum wheat genotypes under mild drought conditions. Int. J. Plant Prod., 4, 11-24. 
Mohammadi, S. A., \& Prasanna, B. M. (2003). Analysis of genetic diversity in crop plants- Salient statistical tools and considerations. Crop Sci., 43, 1234-1248.

Mondal, A. K., Sharma, R. C., Singh, G., \& Dagar, J. C. (2010). Computerised database on salt affected soils in India. Tech. Bull. 2/2010. CSSRI, Karnal.

Nouri, A., Etminan, A., Jaime, A., Silva, T. D., \& Mohammadi, R. (2011). Assessment of yield, yield related traits and drought tolerance of durum wheat genotypes (Triticum turjidumvar. durum Desf.). Aust. J. Crop Sci., 5, 8-16.

Ponnamieruma, P. N. (1984). Role of cultivars tolerance in increasing rice production on saline land. In R. C. Staples \& G. H. Toenniessen (Eds.), Salinity tolerance in plants strategies for crop improvement (pp. 255-71). Wiley, New York.

Richards, R. A. (1996) Defining selection criteria to improve yield under drought. Plant Growth Regul., 20, 157-166.

Rosegrant, M., Paisner, M., Meijer, S., \& Witcover, J. (2001). Global Food Projections to 2020.

Rosielle, A. A., \& Hamblin, J. (1981). Theoretical aspects of selection for yield in stress and non-stress environments. Crop Sci., 21, 943-946.

Singh, S. S. (2012). National Efforts for Increasing Wheat Productivity. Wheat Productivity Enhancement under Changing Climate, 25-30.

Sio-Se Mardeh, A., Ahmadi, A., Poustini, K., \& Mohammadi, V. (2006). Evaluation of drought resistance indices under various environmental conditions. Field Crop Res, 98, 222-229.

SPSS Inc. (2007). SPSS for Windows. Release 16.0.SPSS Inc. Chicago, IL. USA.

Talebi, R., Fayaz, F., \& Naji, N. (2009). Effective selection criteria for assessing drought stress tolerance in durum wheat (Triticum durum Desf.). Gen. Appl. Plant Physiol, 35, 64-74.

Van-Ginkel, M., Calhoun, D. S., Gebeyehu, G., Miranda, A., Tian-you, C., Pargas Lara, R., ... Rajaram, S. (1998). Plant traits related to yield of wheat in early, late, or continuous drought conditions. Euphytica, 100, 109-121.

Zubair, M., Ajmal, S. U., Anwar M., \& Haqqani, M. (2007). Multivariate analysis for quantitative traits in mungbean [Vigna radiate (L.) Wilczek]. Pak. J. Bot, 39, 103-113.

\section{Copyrights}

Copyright for this article is retained by the author(s), with first publication rights granted to the journal.

This is an open-access article distributed under the terms and conditions of the Creative Commons Attribution license (http://creativecommons.org/licenses/by/3.0/). 